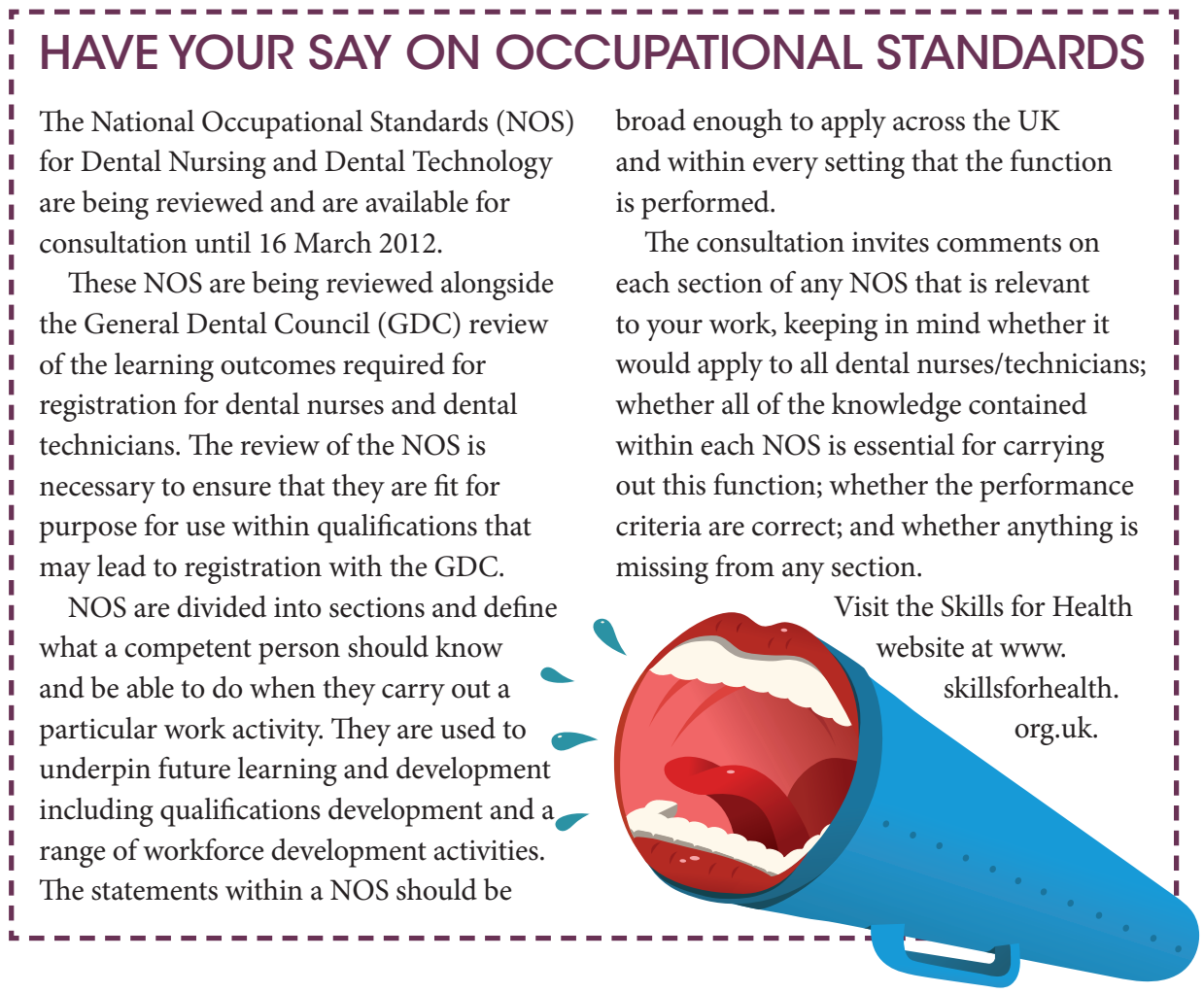

\section{NICKY AND SUE LAUNCH LECTURE SERIES}

Nicky Gough and Sue Bagnall, BSc graduates in Primary Dental Care, are branching out from their online continuing professional development (CPD) website to run a series of lectures for all dental care professionals (DCPs). Initial dates are booked for Birmingham (12 May), Worthing (30 June) and Kent (21 July) and will provide five hours of core verifiable CPD for only $£ 39$ (including tea/coffee and a light lunch).

Nicky told Vital: 'this is an exciting new venture for us. We have decided to branch out so that we can cater for the needs of DCPs who prefer to complete their CPD by attending a traditional lecture.' For more information on dates and booking please see the courses page on www.cpd4dentalnurses.co.uk or email info@cpd4dentalnurses.co.uk.

\section{CRACK DOWN ON ILLEGAL DENTURISTS}

A campaign has been launched to crack down on illegal dentistry across the UK.

The British Association of Clinical Dental Technology (BACDT) has created a website which allows consumers to find a clinical dental technician (CDT) who is registered with the General Dental Council.

Unless a CDT is registered with the General Dental Council (GDC), they are not permitted to provide dentures directly to the public. However, there is a rising number of cases of dental technicians - as opposed to CDTs - breaching the GDC's regulations. Dental technicians are not registered to provide dentures to consumers or work independently in a clinic.

'The BACDT has become increasingly concerned about the rise in illegal dentistry and the website we have launched is aimed at helping to stamp out the problem, said Barrie Semp, a member of the BACDT board and owner of a leading denture clinic. 'Only properly registered CDTs are able to consult patients and provide members of the public with dentures. Dental technicians are usually based in dental laboratories or, with further training, permitted to assist CDTs or dentists.'

Anyone considering using the services of a clinical dental technician should visit the BACDT's website - www. dentureprofessionals.org - and can also verify their choice of CDT by visiting the GDC's website at www.gdc-uk.org.

\title{
DRUG RECOMMENDATIONS PUBLISHED BY BDA
}

The British Dental Association (BDA) has published Prescribing and medicines management which can be downloaded from the BDA website (with a member log-in).

The document outlines the rules and regulations for prescription of controlled drugs, their classifications and the responsibilities for their use, based on advice from the British National Formulary and the UK Medicines Information Service. It also details patient groups to which prescribers may need to give special consideration and how to report adverse reactions. Other topics include prescription writing and Standard operating procedures for controlled drugs.

The guidance covers how practices can set up their own Patient Group Direction (PGD) arrangements. These arrangements in dental practice allow the sale, supply or administration of named medicines in an unidentified clinical situation by dental hygienists or therapists. Medicines legislation was amended in June 2010 to allow them to sell or supply any Pharmacy Medicine or Prescription Only Medicine provided there is a signed written agreement between a dentist, pharmacist and a representative of an appropriate healthcare organisation. This only applies for NHS patients. This legislation enables the sale or supply of prescription-only fluoride supplements and toothpastes containing 2,800 and 5,000 ppm fluoride. Other medicines can be included in a PGD if the hygienist or therapist is assessed as competent in their use.

Any practice that orders, supplies and stores controlled drugs on the premises is required to produce Standard operating procedures that show the pathway of the drug from its acquisition, through its use, to its disposal. www.bda.org/prescribing 